Research Article

\title{
Comprehensive Modification Technology of Involute Spur Gear Based on Optimal Transmission Performance
}

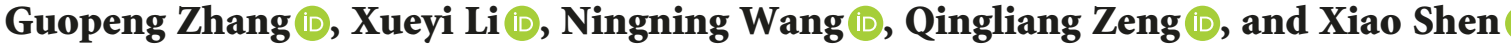 \\ College of Mechanical and Electronic Engineering, Shandong University of Science and Technology, Qingdao 266590, China \\ Correspondence should be addressed to Xueyi Li; lixueyi07@tsinghua.org.cn
}

Received 24 August 2018; Accepted 16 October 2018; Published 8 November 2018

Academic Editor: Ulrich Prahl

Copyright (c) 2018 Guopeng Zhang et al. This is an open access article distributed under the Creative Commons Attribution License, which permits unrestricted use, distribution, and reproduction in any medium, provided the original work is properly cited.

\begin{abstract}
There are some issues that should be solved like load shock, vibration, and uneven load distribution during transmission of involute spur gears. However, common modification methods such as axial modification as well as profile modification could not solve these problems once for all. Hence, a novel method of comprehensive modification was proposed, and the evaluation methodology of transmission performance was drawn up too. Changing modification parameters can control transmission performance of gear unit, which can generate many different modification ways. Besides, based on the orthogonal experiment method and evaluation methodology, optimal modification ways can be chosen for gear pairs working in different conditions. Taking a set of spur gear pair as an example, an ideal modification way was obtained. In addition, analysis results verified that conducting comprehensive modification could enhance the meshing performance once for all.
\end{abstract}

\section{Introduction}

When the gear mechanism transmits power, axial deviation may be generated because of assembly error and teeth deformation. Lias et al. [1] and Korotkin and Gazzaev [2] found that axial deviation seriously affects tooth stresses, and it may lead to uneven load distribution. In addition, there are some other problems in gear units, such as large fluctuation of transmission error (TE) and load shock. They may result in vibration and decreasing the carrying capacity and service life of gear units. Aiming at above problems, conducting modification for gears was researched by many researchers. Thus, teeth surfaces of modified gear are adjusted, and it may improve the meshing performance. For instance, profile modification was performed by Velex et al. [3] to reduce load shock, and the phenomenon of vibration was improved. In addition, axial modifications are often conducted for gears to relieve uneven load distribution. However, most researchers usually consider profile modification and axial modification as two separate issues, and few people take them as a problem. It is conducting profile modification and axial modification at the same time, called comprehensive modification. If gear pairs are modified in this way, the phenomenon of vibration and uneven load distribution can be improved once for all. Nevertheless, how to control modification effects and how to analyze and evaluate the transmission performance become key issues.

Numerous people have researched modification methods for gear mechanism from different aspects at present. For example, Liu and Parker [4] and Chen et al. [5] studied effects of profile modification on dynamic performance of gears, and they found that it can reduce vibration and noises obviously. The method of adjusting parameters of cutting tools to modify gears was studied by Simon [6]. Baglioni et al. [7] explored the influence of modification parameters on transmission efficiency of gear units. Besides, static/dynamic finite element analyses were performed for profile modification gears by $\mathrm{Wu}$ et al. [8]. In addition, Hotait and Kahraman [9] researched the effects of axial deviation and axial modification on load distribution as well as bending stress, and they found that different modification amounts influence modification effects. The tooth surface equation of axial modified gear was deduced based on the 
principle of gear-hobbing and gear-milling by Kawalec and Wiktor [10]. Fuentes et al. [11] compared two different methods of axial modification for spur bevel gears by means of simulation analyses. Moreover, the effects of axial modification, machining error, and other factors on gear strength, carrying capacity, and load distribution were studied by Li $[12,13]$ using finite element analysis, and the influence of profile modification was researched using the same method in the literature [14]. However, all these studies have researched profile modification or axial modification separately, and they did not explore a method to solve load shock, vibration, and uneven load distribution once for all.

Some researchers studied comprehensive modification for cylindrical gear pairs. Huang and Su [15] conducted comprehensive modification for helical gear pairs, and the effect of comprehensive modification on dynamic performance of gear pairs was investigated. But the effects on tooth contact and load distribution were not considered in this study. Taking the contact stress and the fluctuation of TE as objective function, Artoni et al. [16] optimized the comprehensive modification. Simon [17] proposed a comprehensive method for spur and helical gears. A corresponding computer program was developed, and the effects of some key parameters on optimal tooth modifications were analyzed, respectively. However, the method only studied two simple modification curves, linear and parabolic, and the influence of working condition parameters was not considered. Besides, the accurate model for gear pair with comprehensive modification was built by Barbieri et al. [18], and they applied analysis using the accurate model, but they did not explored the method and theory of modification.

In order to overcome shortcomings of the previous studies and solve the problems in gear mechanisms, a novel comprehensive modification method and corresponding evaluation method is proposed in this study. Furthermore, the method of building accurate model for modified gear pairs is introduced, and transient meshing analyses are conducted based on the models. Because transmission performances are controlled by modification parameters which influence the tooth shape, the modification parameters are optimized based on the orthogonal experiment at last. Thus, optimal modification ways can be found for gear pairs working in different conditions.

\section{Comprehensive Modification of Involute Spur Gears}

In practice, the production of modified gears needs secondary operation on the basis of gears that have been produced. Generally, the smaller gear of a gear pair is modified because it has fewer teeth, and manufacturing costs can be reduced. The tooth shape without modification looks like dash-dotted section, as shown in Figures 1(a) and $1(\mathrm{~b})$.

If the gear is only operated with axial modification, the tooth shape will look like dashed section, as shown in Figure $1(\mathrm{a}) . c_{\mathrm{c}}$ is the axial modification amount; $C_{\mathrm{AM}}$ represents the axial modification curve. If the gear is only operated with profile modification, the tooth shape will look like

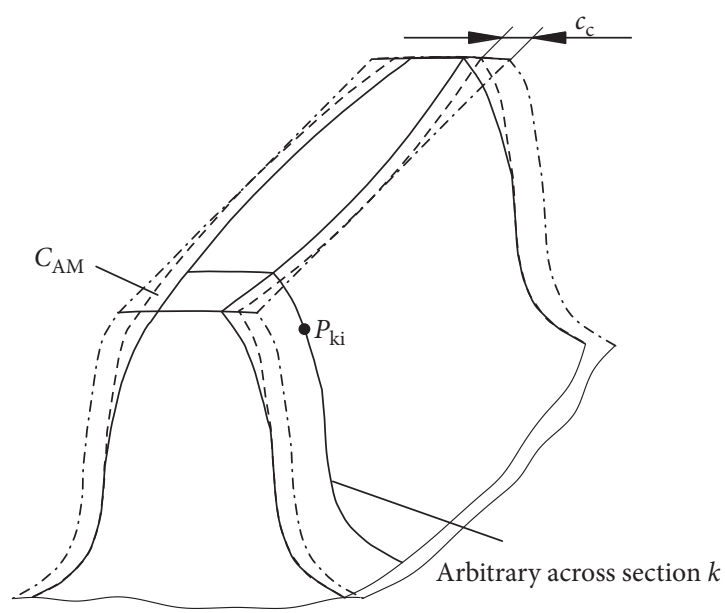

(a)

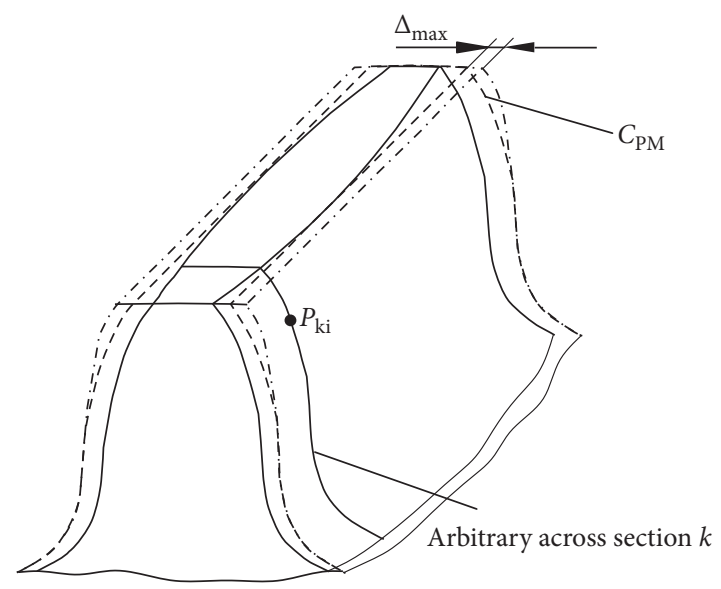

(b)

FIGURE 1: Shape of gear tooth. (a) Conducting axial modification for gear. (b) Conducting profile modification for gear.

dotted section, as shown in Figure 1(b). $\Delta_{\max }$ is the profile modification amount; $C_{\mathrm{PM}}$ represents the profile modification curve. However, it is not only necessary to carry on axial modification but also necessary to conduct profile modification for gear comprehensive modification. Thus, the tooth shape with comprehensive modification looks like the section of solid lines in Figures 1(a) and 1(b). Besides, the value of $c_{\mathrm{c}}$ and $\Delta_{\max }$ are in accordance with the method mentioned in the literature [19]. The point $P_{\mathrm{ki}}$ represents any point at the part of comprehensive modification which is located on cross section of $k$. The cylindrical coordinate system is established by taking the initial point of involute as coordinate origin and the axial direction as the $Z$ axis, and the coordinate system is located at the gear face. Thus, the coordinates of $P_{k i}$ can be described as follows:

$$
\left\{\begin{array}{l}
r_{k i}=\sqrt{r_{\mathrm{a}}^{2}+\left(l-l_{\mathrm{ki}}\right)^{2}-2 r_{\mathrm{a}} \cdot\left(l-l_{\mathrm{ki}}\right) \sin \alpha_{\mathrm{a}}} \\
\theta_{\mathrm{ki}}=\left(\theta_{1 \mathrm{ki}}+\theta_{2 \mathrm{ki}}-\theta_{3 \mathrm{ki}}\right) \cdot \frac{180}{\pi}+\theta_{\mathrm{k}}, \\
z_{\mathrm{ki}}=z_{\mathrm{k}} .
\end{array}\right.
$$


where $r_{\mathrm{a}}$ is the addendum circle radius, $l$ represents the profile modification length, $l_{\mathrm{ki}}$ is the modification length of point $P_{\mathrm{ki}}, \alpha_{\mathrm{a}}$ is the pressure angle of addendum circle, and $z_{\mathrm{k}}$ represents the coordinate of the $Z$ axis. Besides, $l$ can be calculated as follows:

$$
l=(\varepsilon-1) \cdot m_{\mathrm{t}} \cdot \cos \alpha_{\mathrm{t}} \cdot \pi,
$$

where $\varepsilon$ is the contact ratio of gear pair, $m_{\mathrm{t}}$ is the transverse module, and $\alpha_{\mathrm{t}}$ represents the transverse pressure angle.

In addition, $\theta_{1 \mathrm{ki}}, \theta_{2 \mathrm{ki}}, \theta_{3 \mathrm{ki}}$, and $\theta_{\mathrm{k}}$ in Equation (1) can be calculated, respectively, as the following equation:

$$
\left\{\begin{aligned}
\theta_{1 \mathrm{ki}} & =\tan \alpha_{\mathrm{ki}}-\alpha_{\mathrm{ki}}, \\
\theta_{2 \mathrm{ki}} & =\frac{s_{\mathrm{ki}}}{2 r_{\mathrm{ki}}} \\
\theta_{3 \mathrm{ki}} & =\arctan \left(\frac{\left(r_{\mathrm{ki}} \cdot \sin \theta_{2 \mathrm{ki}}-\Delta_{\mathrm{ki}}\right)}{l_{\mathrm{ki}}}\right), \\
\theta_{\mathrm{k}} & =\frac{c_{\mathrm{k}}}{r_{\mathrm{a}}} \cdot \frac{180}{\pi} .
\end{aligned}\right.
$$

In Equation (3), $\alpha_{\mathrm{ki}}$ is the pressure angle of point $P_{\mathrm{ki}}, s_{\mathrm{ki}}$ is the tooth thickness of this point, $\Delta_{\mathrm{ki}}$ represents the profile modification value of point $P_{\mathrm{ki}}$, and $c_{\mathrm{k}}$ is the axial modification value of cross section $\mathrm{k}$. Moreover, $\alpha_{\mathrm{ki}}, \Delta_{\mathrm{ki}}$, and $c_{\mathrm{k}}$ can be calculated, respectively, as Equations (4)-(6):

$$
\begin{aligned}
\alpha_{\mathrm{ki}} & =\alpha_{\mathrm{a}}-\arcsin \left(\cos \alpha_{\mathrm{a}} \cdot \frac{l-l_{\mathrm{ki}}}{r_{\mathrm{ki}}}\right), \\
\Delta_{\mathrm{ki}} & =\Delta_{\max } \cdot\left(\lambda \cdot\left(\frac{l_{\mathrm{ki}}}{l}\right)^{\gamma}+(1-\lambda) \cdot\left(\frac{l_{\mathrm{ki}}}{l}\right)^{\beta}\right), \\
c_{\mathrm{k}} & =c_{\mathrm{c}} \cdot\left(\omega \cdot\left(\frac{z_{\mathrm{k}}}{b_{\mathrm{c}}}\right)^{\eta}+(1-\omega) \cdot\left(\frac{z_{\mathrm{k}}}{b_{\mathrm{c}}}\right)^{\varphi}\right),
\end{aligned}
$$

where $\lambda$ is the superposition coefficient, $0 \leq \lambda \leq 1, \gamma$ and $\beta$ are the power, $1 \leq \gamma \leq 3,1 \leq \beta \leq 3$, and these three coefficients control the shape of profile modification curve. Besides, $\omega$ is the superposition coefficient of the axial modification curve, $0 \leq \omega \leq 1, \eta$ and $\varphi$ are the power, $1 \leq \eta \leq 3,1 \leq \phi \leq 3$, and these three coefficients control the shape of the axial modification curve. $b_{c}$ represents the distance from the center of axial modification to the closer tooth face.

As for the part without comprehensive modification of the tooth surface, it is same with usual axial modification. Hence, coordinates of points located on this part are not introduced here.

\section{Transmission Performance Evaluation of Modified Gear Pair}

The finite element method is widely used in structural analysis with development of CAE technology, and details such as deformation and stress about the mechanical structure can be obtained in this way. Therefore, the finite element method is used to analyze the transmission performance of gears with comprehensive modification in this study. In addition, the model used for analysis should be built before that.

To avoid data loss and the destruction of model when transfer data between different software, models of modified gear pairs can be built in ANSYS using APDL (ANSYS Parametric Design Language) based on previous study [20]. The shape of the tooth surface is complex after applying comprehensive modification because it is affected by two modification curves mentioned above. In addition, the contact condition between tooth surfaces has a great influence on stresses and others, so the tooth surface must be accurate enough. According to the method mentioned above, coordinates of points located on the tooth surface can be calculated. In order to facilitate gear solid modeling, the gird lattice of a single tooth surface as shown in Figure 2(a) is calculated. In addition, the tooth surface is fitted by every point in the matrix, as shown in Figure 2(b).

Based on the tooth surface established above, the model of gear pair with comprehensive modification can be build according to the method mentioned in the literature [19]. The model of a gear pair is meshed with the mapping method in this study, then establishing contact pairs, and applying loads as well as constraints to the model, and the finite element model of a gear pair with comprehensive modification can be described as shown in Figure 3.

Conducting transient meshing analysis on the basis of the finite element model, transmission performance can be acquired by reading the analysis results. Contour map of contact stress of modified gear pair can reflect the contact condition and the shape of contact area. Hence, reading contour map of contact stress as Figure 4, it can be found that the shape of the contact area is narrow and long, which means contact condition is well and the phenomenon of uneven load distribution is improved. Besides, the value of contact stress can be obtained from the figure too.

Moreover, reading rotations of drive gear and driven gear, respectively, the transmission error can be calculated. The transmission error curve can be drawn as shown in Figure 5. If a pair of gears is modified using different modification ways, the fluctuation of TE will be different. Smaller fluctuation reflects better modification effect.

In addition, load distribution, root bending stress, and the distance from modification center to tooth width center can also be read; thus, transmission performance can be evaluated.

\section{Optimizing Modification Parameters to Control Transmission Performance}

The shape of the tooth surface directly affects the transmission performance of a gear pair. Therefore, finding ideal modification ways for different gear pairs to get optimal transmission performance becomes a key issue researched in this study.

As mentioned above, the shape of the tooth surface is controlled by two modification curves, and it can be changed 


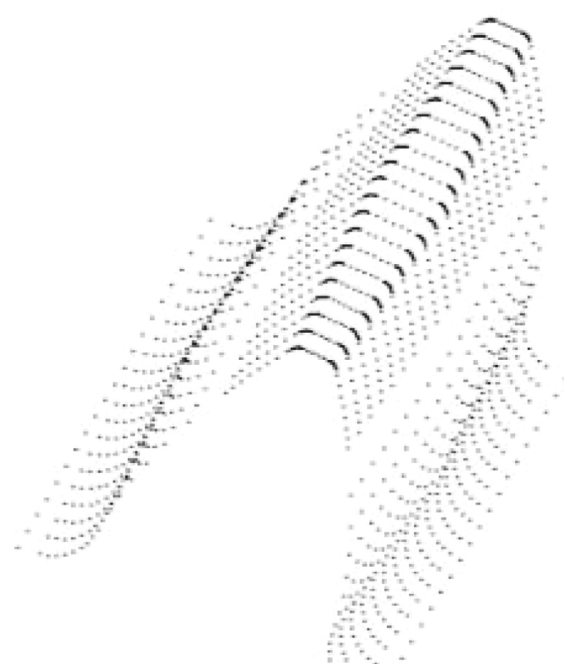

(a)

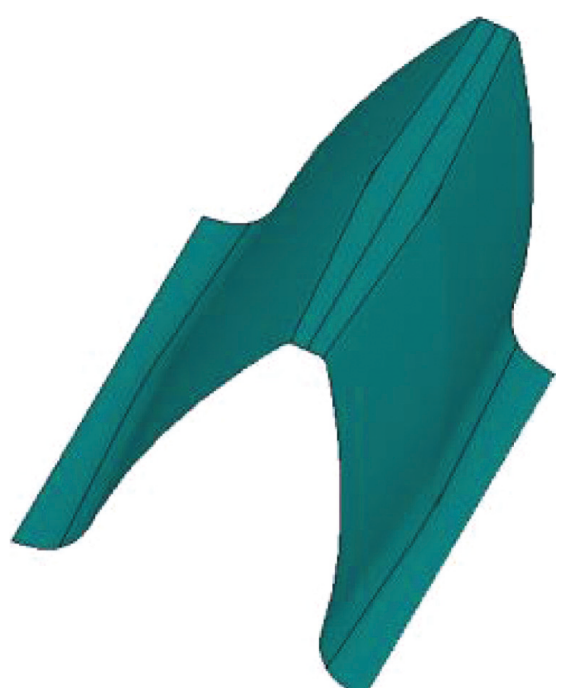

(b)

FIgURE 2: Fitting tooth surface. (a) Grid lattice of a single tooth surface. (b) Tooth surface.

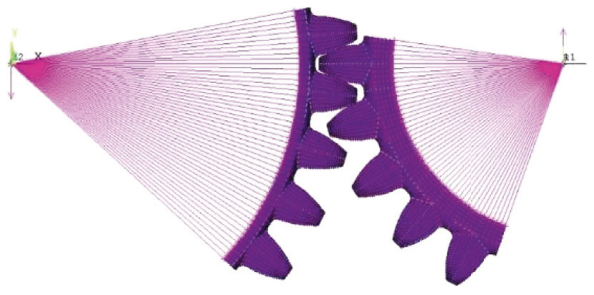

Figure 3: Finite element model of modified gear pair.

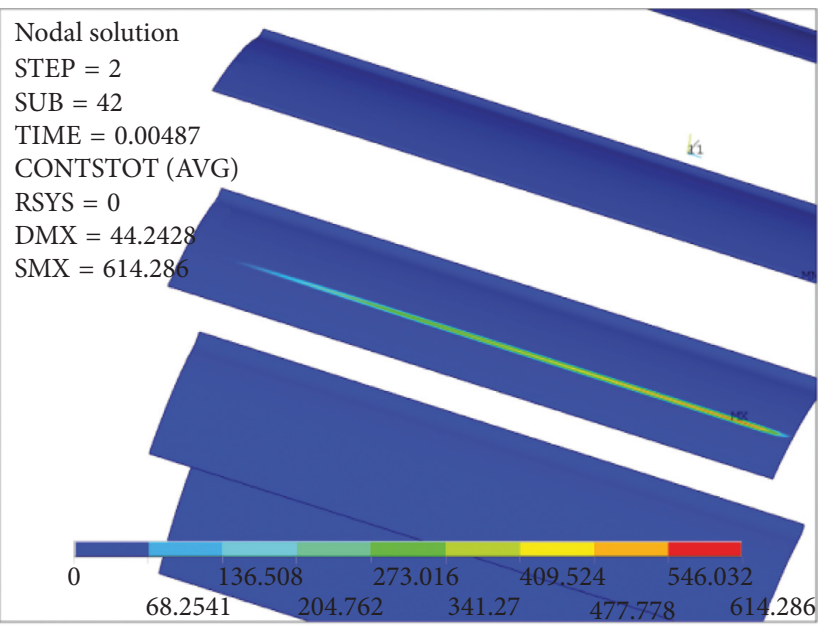

Figure 4: Contour map of contact stress.

by controlling parameters which influence these two modification curves. Referring to the previous study [21], ideal modification way is optimized through the orthogonal experiment. In addition, parameters that control modification effects and transmission performance are influence factors, and they are $\lambda, \gamma, \beta, \omega, \eta$, and $\varphi$. Considered about the efficiency of the orthogonal experiment and the effect,

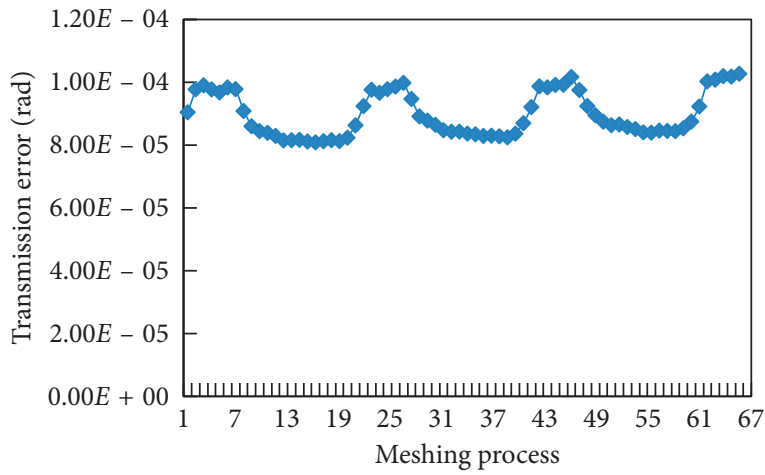

Figure 5: Curve of transmission error.

every influence factor is divided into 5 levels in this study. The orthogonal experiment scheme is arranged according to the orthogonal table $L_{25}\left(5^{6}\right)$, which is as shown in Table 1.

According to the scheme listed above, simulation analyses are conducted for the gear pair using data listed in Table 1 . When the analyses are finished in turn, corresponding performance parameters such as root bending stress, contact stress, and fluctuation of transmission error for each modified gear pair can be obtained.

The determination of the best modification way is a multiobjective optimization problem, which should minimize the fluctuation of the transmission error, root bending stress, and contact stress of the modified gear pair. Usually, it is difficult to achieve this. Compared with root bending stress and contact stress, the fluctuation of the transmission error is more sensitive to modification parameters. To determine the ideal modification way, according to the analysis result of the orthogonal experiment, several schemes with small fluctuation of the transmission error are selected first. Then, from these schemes, the scheme with the best contact area and satisfying contact stress and root bending stress is selected, which is the ideal modification scheme. 
TABLE 1: Scheme of orthogonal experiment.

\begin{tabular}{lcccccc}
\hline \multirow{2}{*}{ Test } & $\lambda$ & $\gamma$ & $\beta$ & $\omega$ & $\eta$ & $\varphi$ \\
\hline 1 & 0.1 & 1 & 1 & 0.1 & 1 & 1 \\
2 & 0.1 & 1.5 & 1.5 & 0.3 & 1.5 & 1.5 \\
3 & 0.1 & 2 & 2 & 0.5 & 2 & 2 \\
4 & 0.1 & 2.5 & 2.5 & 0.7 & 2.5 & 2.5 \\
5 & 0.1 & 3 & 3 & 0.9 & 3 & 3 \\
6 & 0.3 & 1 & 1.5 & 0.5 & 2.5 & 3 \\
7 & 0.3 & 1.5 & 2 & 0.7 & 3 & 1 \\
8 & 0.3 & 2 & 2.5 & 0.9 & 1 & 1.5 \\
9 & 0.3 & 2.5 & 3 & 0.1 & 1.5 & 2 \\
10 & 0.3 & 3 & 1 & 0.3 & 2 & 2.5 \\
11 & 0.5 & 1 & 2 & 0.9 & 1.5 & 2.5 \\
12 & 0.5 & 1.5 & 2.5 & 0.1 & 2 & 3 \\
13 & 0.5 & 2 & 3 & 0.3 & 2.5 & 1 \\
14 & 0.5 & 2.5 & 1 & 0.5 & 3 & 1.5 \\
15 & 0.5 & 3 & 1.5 & 0.7 & 1 & 2 \\
16 & 0.7 & 1 & 2.5 & 0.3 & 3 & 2 \\
17 & 0.7 & 1.5 & 3 & 0.5 & 1 & 2.5 \\
18 & 0.7 & 2 & 1 & 0.7 & 1.5 & 3 \\
19 & 0.7 & 2.5 & 1.5 & 0.9 & 2 & 1 \\
20 & 0.7 & 3 & 2 & 0.1 & 2.5 & 1.5 \\
21 & 0.9 & 1 & 3 & 0.7 & 2 & 1.5 \\
22 & 0.9 & 1.5 & 1 & 0.9 & 2.5 & 2 \\
23 & 0.9 & 2 & 1.5 & 0.1 & 3 & 2.5 \\
24 & 0.9 & 2.5 & 2 & 0.3 & 1 & 3 \\
25 & 0.9 & 3 & 2.5 & 0.5 & 1.5 & 1 \\
\hline & & & & & &
\end{tabular}

\section{Simulation Example and Comparative Analysis}

Based on the developed program, several pairs of gears under different working conditions were selected for the modification simulation, and ideal comprehensive modification ways can be obtained by changing parameters which control the shape of the tooth surface. Taking a pair of gears in a reducer used in an automobile as an example, the specific implementation process is introduced in detail to verify the rationality and validity of the method described, and parameters of the gear pair are shown in Table 2.

The allowable value of contact fatigue stress of the gear pair shown in Table 2 is $1080.0 \mathrm{MPa}$, and the allowable value of bending fatigue stress is $376.43 \mathrm{MPa}$. Transient meshing analyses are conducted for the gear pair with comprehensive modification using data shown in Table 1. The results of these analyses are summarized in Table 3, included contact stress, root bending stress, and the distance from the contact area to the center of tooth width. Besides, standard deviation of TE is calculated to reflect the fluctuation of TE.

It can be found that values of standard deviation of TE in tests including number $4,5,6,10,12,22$, and 23 are smaller than $0.5 \times 10^{-5} / \mathrm{rad}$. In these 7 tests, considering stresses and the distance from the contact area to the center of tooth width, modification effect is the best when the gear pair is modified with 5th set of parameters. The distance from the contact area to the center of tooth width is shortest in this test, and the contact stress is $609.33 \mathrm{MPa}$, which is smaller than the allowable value. Besides, the root bending stress of
TABLE 2: Parameters of gear pair.

\begin{tabular}{lcc}
\hline Tooth number & Drive gear & 18 \\
Modulus $m$ & Driven gear & 55 \\
Pressure angle $\alpha\left(^{\circ}\right)$ & 6 \\
Modification coefficient & & 20 \\
& Drive gear $x 1$ & 0.54 \\
Tooth width $(\mathrm{mm})$ & Driven gear $x 2$ & 0.5548 \\
The rotate speed of drive gear (r/min) & 68 \\
The torque of drive gear $(\mathrm{Nm})$ & Drive gear $B 1$ & 64 \\
Load factor & & 1484 \\
& & 400 \\
\end{tabular}

TABLE 3: Results of orthogonal.

\begin{tabular}{|c|c|c|c|c|c|}
\hline \multirow[b]{2}{*}{$\begin{array}{l}\text { Test } \\
\text { number }\end{array}$} & \multicolumn{5}{|c|}{ Experiment results } \\
\hline & $\begin{array}{c}\text { Contact } \\
\text { stress } \\
(\mathrm{MPa})\end{array}$ & $\begin{array}{c}\text { Bending } \\
\text { stress of } \\
\text { drive } \\
\text { gear } \\
(\mathrm{MPa})\end{array}$ & $\begin{array}{c}\text { Bending } \\
\text { stress of } \\
\text { driven } \\
\text { gear } \\
(\mathrm{MPa})\end{array}$ & $\begin{array}{c}\text { Standard } \\
\text { deviation } \\
\text { of } \\
\mathrm{TE} \times 10^{-5} \\
(\mathrm{rad})\end{array}$ & $\begin{array}{l}\text { Distance } \\
\text { between } \\
\text { contact pot } \\
\text { to center of } \\
\text { tooth width } \\
(\mathrm{mm})\end{array}$ \\
\hline 1 & 730.40 & 83.34 & 91.35 & 2.16 & 30.6 \\
\hline 2 & 662.72 & 99.38 & 87.98 & 1.28 & 30.6 \\
\hline 3 & 626.14 & 102.25 & 86.28 & 0.70 & 28.9 \\
\hline 4 & 610.93 & 112.28 & 85.43 & 0.35 & 27.2 \\
\hline 5 & 609.33 & 109.87 & 85.91 & 0.30 & 23.8 \\
\hline 6 & 680.42 & 94.54 & 88.37 & 0.30 & 30.6 \\
\hline 7 & 636.63 & 101.69 & 86.27 & 0.70 & 30.6 \\
\hline 8 & 614.04 & 113.24 & 86.38 & 2.04 & 28.9 \\
\hline 9 & 609.79 & 116.58 & 86.89 & 0.73 & 27.2 \\
\hline 10 & 678.61 & 101.52 & 89.47 & 0.46 & 30.6 \\
\hline 11 & 672.78 & 100.64 & 88.82 & 1.19 & 30.6 \\
\hline 12 & 632.44 & 101.31 & 86.15 & 0.28 & 28.9 \\
\hline 13 & 614.29 & 113.59 & 86.48 & 1.58 & 27.2 \\
\hline 14 & 660.16 & 100.41 & 88.34 & 0.67 & 30.6 \\
\hline 15 & 627.26 & 111.03 & 87.15 & 1.70 & 28.9 \\
\hline 16 & 684.32 & 97.83 & 89.47 & 0.53 & 30.6 \\
\hline 17 & 639.04 & 102.28 & 86.92 & 1.23 & 28.9 \\
\hline 18 & 653.89 & 99.5 & 87.48 & 0.92 & 30.6 \\
\hline 19 & 622.64 & 109.88 & 86.52 & 0.84 & 28.9 \\
\hline 20 & 612.56 & 113.85 & 87.17 & 1.16 & 27.2 \\
\hline 21 & 707.01 & 94.44 & 90.91 & 0.89 & 30.6 \\
\hline 22 & 668.68 & 95.66 & 87.64 & 0.40 & 30.6 \\
\hline 23 & 629.24 & 100.89 & 85.76 & 0.35 & 28.9 \\
\hline 24 & 611.57 & 112.68 & 85.62 & 0.69 & 27.2 \\
\hline 25 & 609.44 & 117.41 & 87.48 & 1.68 & 27.2 \\
\hline
\end{tabular}

drive gear in this test is $109.87 \mathrm{MPa}$, and the root bending stress of driven gear is $85.91 \mathrm{MPa}$; both of them are less than allowable values. That means applying comprehensive modification to the gear pair with optimized parameters can meet the strength requirements.

Furthermore, in order to verify the comprehensive modification effects, transient meshing analysis is performed for the gear pair shown in Table 2 without modification and comparing its results with results of test 5 . The contact stress is $995.23 \mathrm{MPa}$ in this situation, the root bending stress of drive gear is $102.01 \mathrm{MPa}$, and the root bending stress of driven gear is $115.51 \mathrm{MPa}$. It can be found that the gear pair 


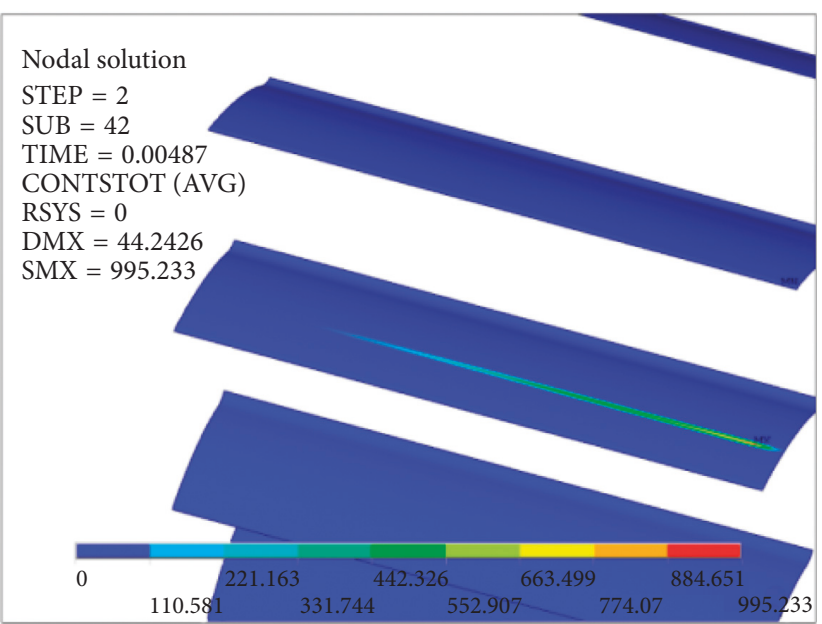

(a)

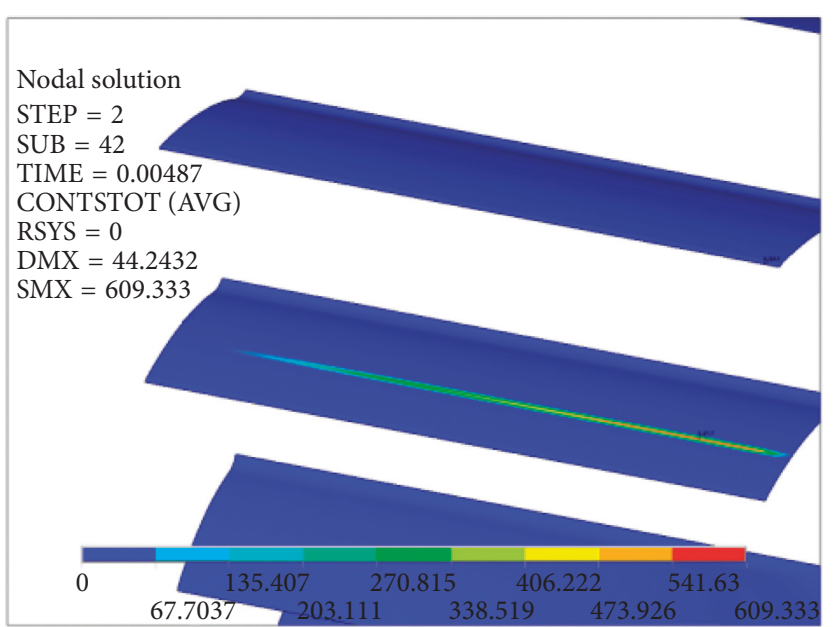

(b)

Figure 6: Contour map of contact stress. (a) Without modification. (b) Comprehensive modification.

is barely meet strength requirement without modification. The contour map of contact stress is acquired as shown in Figure 6(a), while the contour map of test 5 is as shown in Figure 6(b). Comparing these two pictures, it can be found that there is serious phenomenon of uneven load distribution during the transmission, and conducting comprehensive modification can obviously improve this phenomenon.

The values of contact stress are read along tooth width, respectively, for the gear pair without modification and test 5 , and the distribution curve can be drawn as shown in Figure 7. Thus, effect of comprehensive modification on the phenomenon of uneven load distribution is compared visually. It can be found that the distribution of contact stress of the gear pair without comprehensive modification is a slope because of axial deviation, and the maximum value is very high. While conducting comprehensive modification to the gear pair, the distribution is relatively smooth. That means, the phenomenon of uneven load distribution has been improved, and the maximum value of contact stress is declined obviously.

Besides, the value of load on the tooth surface during the meshing process is read, and distribution curves are drawn in Figure 8. Load on the tooth surface has abrupt changes, and these abrupt changes are load shocks. Thus, it may lead to vibration for gear mechanism. If the gear pair is modified with optimized parameters, load on the tooth surface increases gradually to the maximum when the tooth starts meshing. After some time, the load decreases gradually from the maximum to zero when the tooth takes off meshing. Thus, the phenomenon of load shock can be dramatically improved.

The value of the transmission error can be read in these two situations, and curves of TE are drawn in Figure 9. It can be found that the fluctuation of TE in a gear pair without modification is large, and the standard deviation is $1.31 \times$ $10^{-5} / \mathrm{rad}$. As for the situation with comprehensive modification, there are still cyclical fluctuations of TE, but the amplitude is decreased obviously. Besides, the standard deviation is $0.30 \times 10^{-5} / \mathrm{rad}$, which is smaller. Therefore,

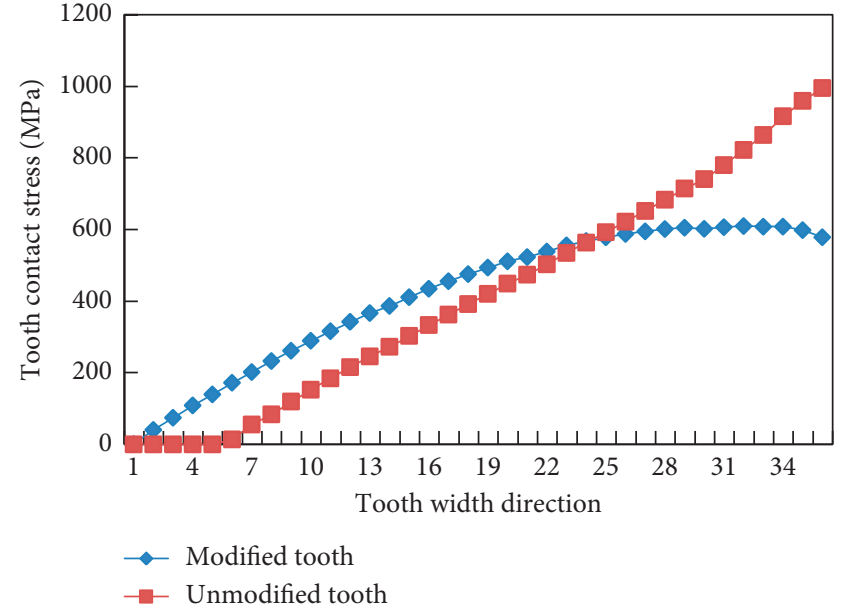

Figure 7: Distribution of contact stress.

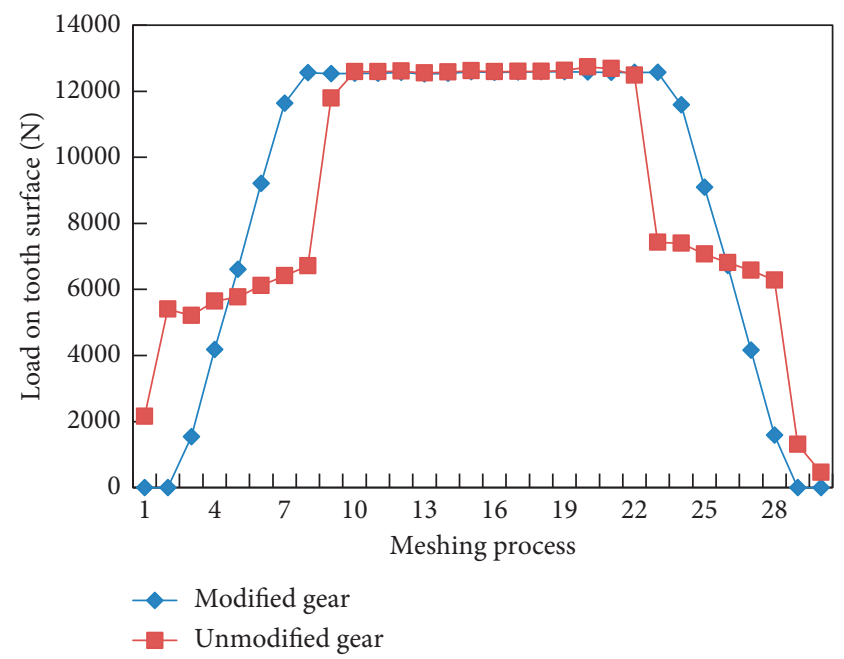

Figure 8: Load on tooth surface. 


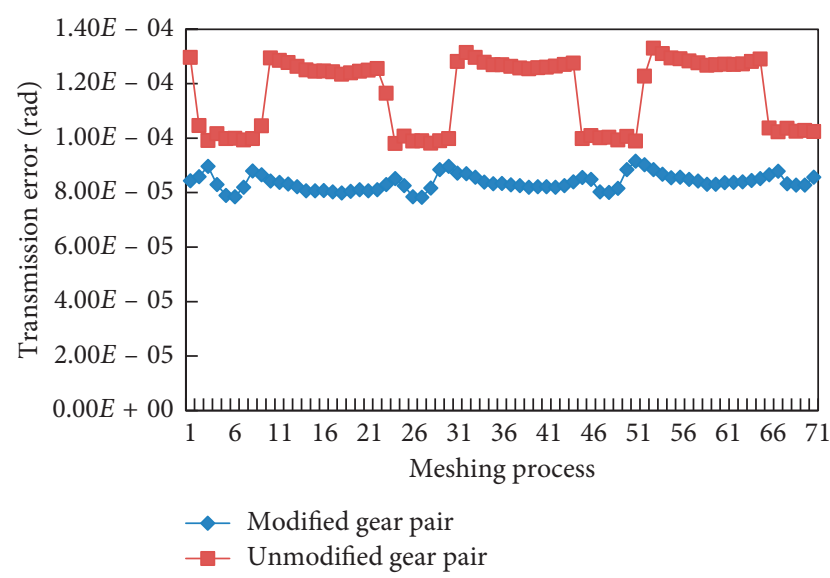

FIGURE 9: Fluctuation of transmission error.

conducting comprehensive modification can decrease the fluctuation of TE, and vibration as well as noise resulting from it can be reduced too.

\section{Conclusions}

Taking a pair of gears as an example, the comprehensive modification method proposed in this study is applied to the gear pair. Changing parameters which control the shape of the tooth surface, optimal transmission performance can be obtained for the gear pair based on conducting the orthogonal experiment. Through lots of results of simulation and comparative analysis, the following conclusions can be summarized:

(1) Conducting comprehensive modification can reduce load shock in the gear pairs and improve the phenomenon of vibration and noise because of large fluctuation of the transmission error.

(2) Conducting comprehensive modification can improve the phenomenon of uneven load distribution result from axial deviation.

(3) Modification effects are influenced by parameters which control the shape of the tooth surface.

(4) Using the method proposed in this study, optimal transmission performance can be obtained for gear pairs.

\section{Data Availability}

The data used to support the findings of this study are available from the corresponding author upon request.

\section{Conflicts of Interest}

The authors declare that there are no conflicts of interest regarding the publication of this paper.

\section{Acknowledgments}

This work was supported by the National Natural Science Foundation of China (Grant no. 51674155), the Science and
Technology Development Program of Shandong Province (Grant no. 2017GGX30127), the Special Funds for Cultivation of Taishan Scholars, the Shandong Provincial Natural Science Foundation of China (Grant no. ZR2016EEQ24), and the Postgraduate Technology Innovation Project of Shandong University of Science and Technology of China (Grant no. SDKDYC180219).

\section{References}

[1] M. R. Lias, M. Awang, and T. V. V. L. N. Rao, "A numerical FEM solution of gear root stress in offset axial mesh misalignment," Applied Mechanics and Materials, vol. 393, pp. 375-380, 2013.

[2] V. I. Korotkin and D. A. Gazzaev, "Axial error of gears and the tooth stress state in involute gear systems," Russian Engineering Research, vol. 31, no. 9, pp. 834-837, 2011.

[3] Ph Velex, M. Chapron, H. Fakhfakh et al., "On transmission errors and profile modifications minimising dynamic tooth loads in multi-mesh gears," Journal of Sound and Vibration, vol. 379, pp. 28-52, 2016.

[4] G. Liu and R. G. Parker, "Dynamic modeling and analysis of tooth profile modification for multimesh gear vibration," Journal of Mechanical Design, vol. 130, no. 12, article 121402, 2008.

[5] S. Y. Chen, J. Y. Tang, W. T. Chen, Z. Hu, and M. Cao, "Nonlinear dynamic characteristic of a face gear drive with effect of modification," Meccanica, vol. 49, no. 5, pp. 10231037, 2014.

[6] V. Simon, "Head-cutter for optimal tooth modifications in spiral bevel gears," Mechanism and Machine Theory, vol. 44, no. 7, pp. 1420-1435, 2009.

[7] S. Baglioni, F. Cianetti, and L. Landi, "Influence of the addendum modification on spur gear efficiency," Mechanism and Machine Theory, vol. 49, pp. 216-233, 2012.

[8] Y. J. Wu, J. J. Wang, and Q. K. Han, "Static/dynamic contact FEA and experimental study for tooth profile modification of helical gears," Journal of Mechanical Science and Technology, vol. 26, no. 5, pp. 1409-1417, 2012.

[9] M. Hotait and A. Kahraman, "Experiments on root stresses of helical gears with lead crown and misalignments," Journal of Mechanical Design, vol. 130, no. 7, article 074502, 2008.

[10] A. Kawalec and J. Wiktor, "Simulation of generation and tooth contact analysis of helical gears with crowned flanks," Proceedings of the Institution of Mechanical Engineers. Part B: Engineering Manufacture, vol. 222, no. 9, pp. 1147-1160, 2008.

[11] A. Fuentes, J. L. Iserte, I. Gonzalez-Perez, and F. T. SanchezMarin, "Computerized design of advanced straight and skew bevel gears produced by precision forging," Computer Methods in Applied Mechanics and Engineering, vol. 200, no. 29-32, pp. 2363-2377, 2011.

[12] S. T. Li, "Effects of machining errors, assembly errors and tooth modifications on loading capacity, load-sharing ratio and transmission error of a pair of spur gears," Mechanism and Machine Theory, vol. 42, no. 6, pp. 698-726, 2007.

[13] S. T. Li, "Finite element analyses for contact strength and bending strength of a pair of spur gears with machining errors, assembly errors and tooth modifications," Mechanism and Machine Theory, vol. 42, no. 1, pp. 88-114, 2007.

[14] S. T. Li, "Effects of misalignment error, tooth modifications and transmitted torque on tooth engagements of a pair of spur gears," Mechanism and Machine Theory, vol. 83, pp. 125-136, 2015. 
[15] K. J. Huang and C. Y. Su, "An investigation on helical gear pair stresses incorporating misalignment and detail modification," Journal of Vibroengineering, vol. 15, no. 1, pp. 90-99, 2013.

[16] A. Artoni, M. Guiggiani, A. Kahraman, and J. Harianto, "Robust optimization of cylindrical gear tooth surface modifications within ranges of torque and misalignments," Journal of Mechanical Design, vol. 135, no. 12, article 121005, 2013.

[17] V. Simon, "Optimal tooth modifications for spur and helical gears," ASME Journal of Mechanisms, Transmissions and Automation in Design, vol. 111, no. 4, pp. 611-615, 1989.

[18] M. Barbieri, A. Zippo, and F. Pellica, "Adaptive grid-size finite element modeling of helical gear pairs," Mechanism and Machine Theory, vol. 82, pp. 17-32, 2014.

[19] Gear Handbook Editorial Committee, Gear Handbook, Mechanical Industry Press, Beijing, China, 2nd edition, 2004.

[20] X. Y. Li, Y. F. Cui, N. N. Wang, and Q. L. Zeng, "Precision modeling and meshing analysis of cylindrical gear based on hobbing principle," Computer Integrated Manufacturing Systems, CIMS, vol. 22, no. 7, pp. 1679-1686, 2016.

[21] X. Y. Li, N. N. Wang, Y. G. Lv, and Q. L. Zeng, "Tooth profile modification and simulation analysis of involute spur gear," International Journal of Simulation Modeling, vol. 15, no. 4, pp. 649-662, 2016. 


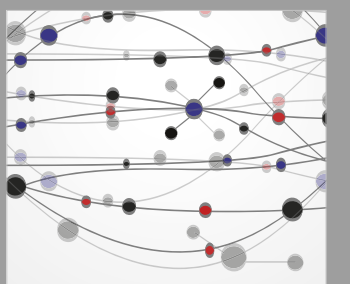

The Scientific World Journal
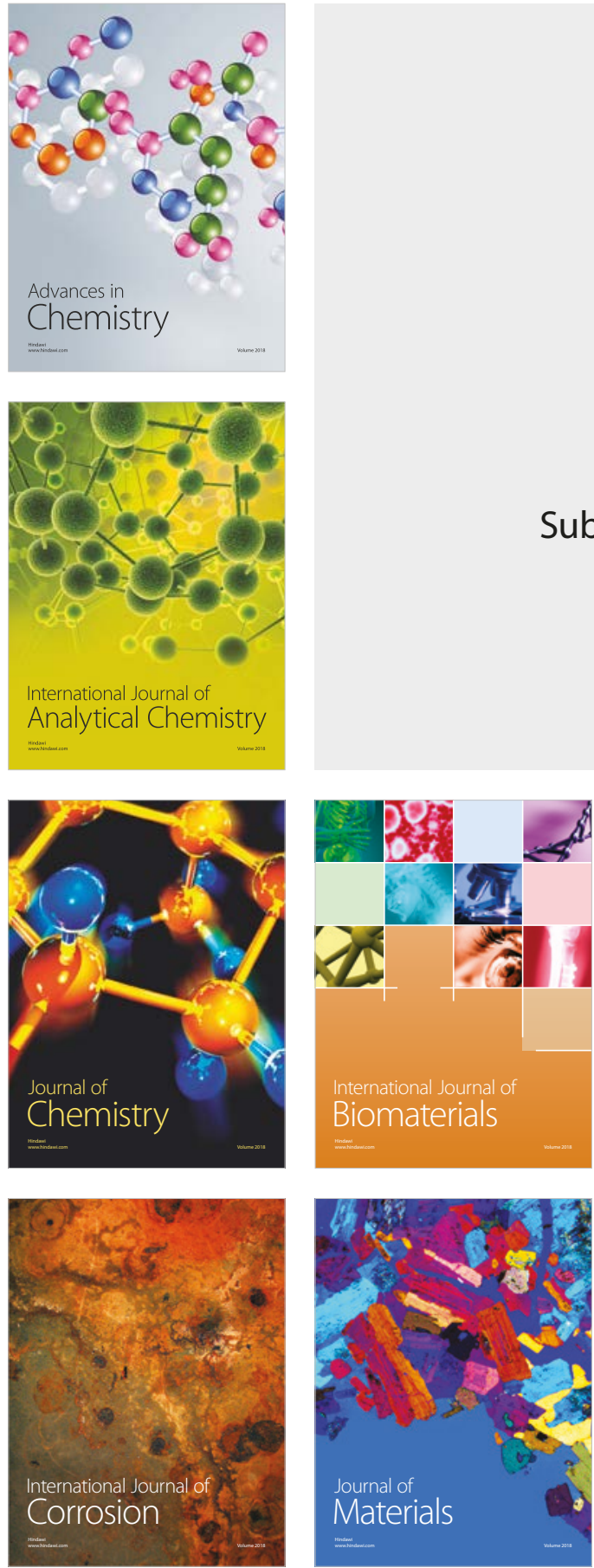

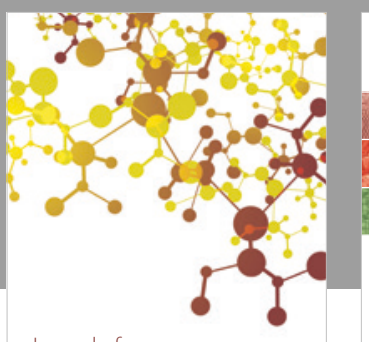

Journal of

Applied Chemistry
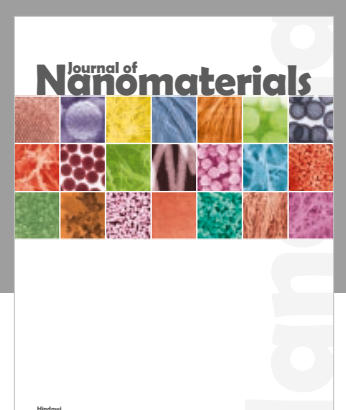

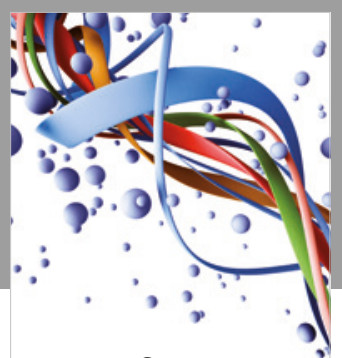

Scientifica

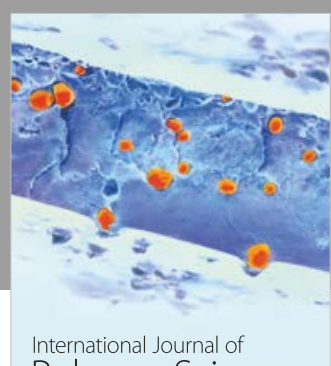

Polymer Science

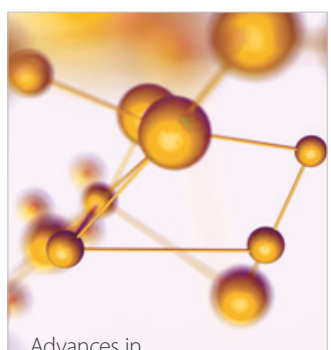

Physical Chemistry
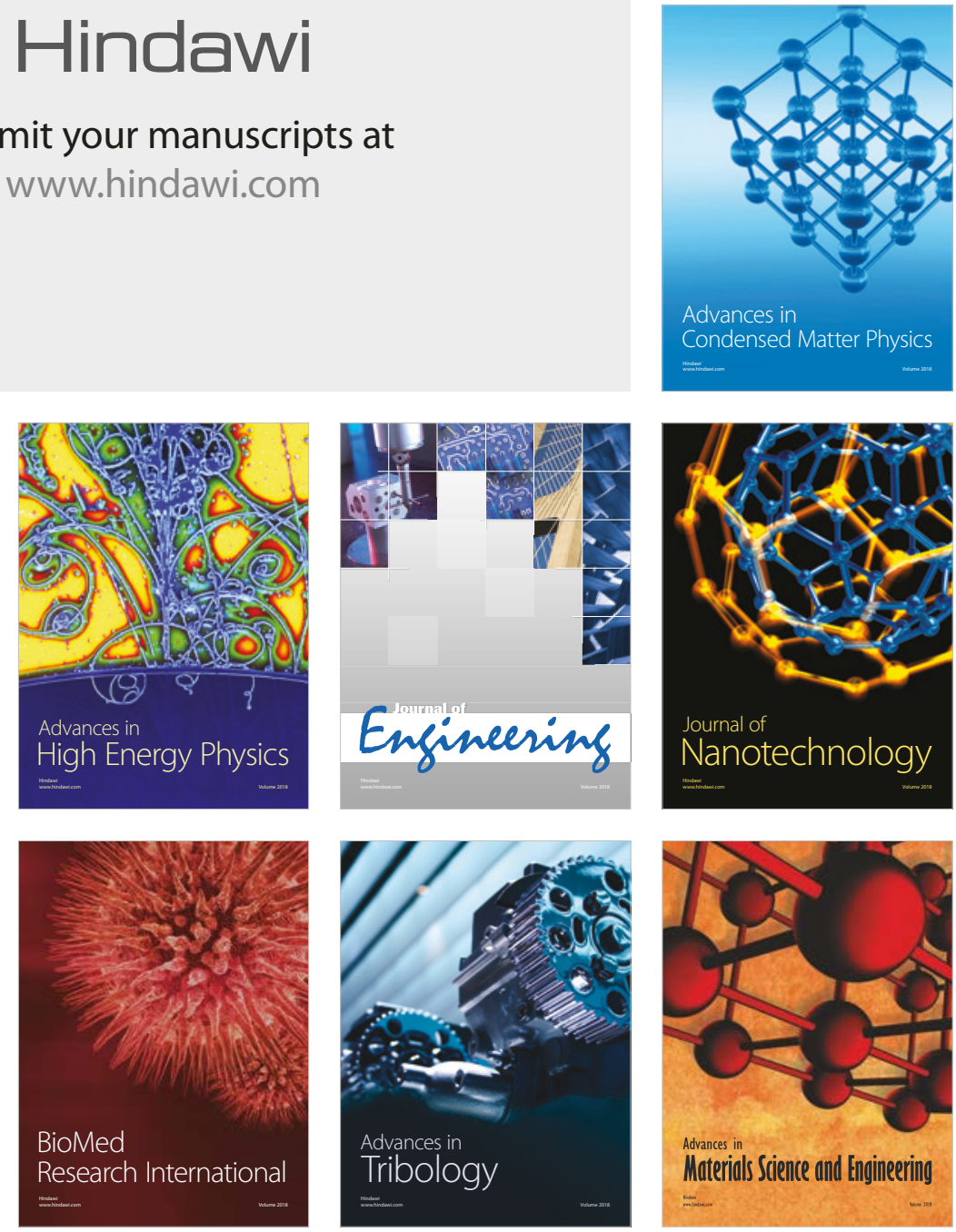